Received Date : 29-Feb-2016

Revised Date : 30-Sep-2016

Accepted Date : 06-Oct-2016

Article type : Original Paper

\title{
Sex specific vitamin D effects on blood coagulation among overweight adults
}

Nasser M. Al-Daghri, ${ }^{1,2 *}$, Majed S. Alokail ${ }^{1,2}$, Antigoni Manousopoulou ${ }^{3,4}$, Ashley Heinson ${ }^{3}$, Omar AlAttas $^{2}$, Yousef Al-Saleh ${ }^{2}$, Shaun Sabico ${ }^{1,2}$, Sobhy Yakout ${ }^{1,2}$, Christopher H. Woelk ${ }^{3}$, George P. Chrousos $^{6}$ and Spiros D. Garbis $^{3,4,5 *}$

${ }^{I}$ Biomarkers Research Program, Biochemistry Department, College of Science, King Saud University, KSA;

${ }^{2}$ Prince Mutaib Chair for Biomarkers of Osteoporosis, Biochemistry Department, King Saud University, KSA;

${ }^{3}$ Clinical and Experimental Sciences, Faculty of Medicine, University of Southampton, Southampton General Hospital, UK,

${ }^{4}$ Centre for Proteomic Research, Institute for Life Sciences, University of Southampton, UK;

${ }^{5}$ Cancer Sciences, Faculty of Medicine, University of Southampton, Southampton General Hospital, UK;

${ }^{6} 1$ st Department of Pediatrics, University of Athens, Greece.

*To whom correspondence should be addressed:

\section{Spiros D. Garbis, PhD}

Faculty of Medicine, University of Southampton, Southampton, UK

This article has been accepted for publication and undergone full peer review but has not been through the copyediting, typesetting, pagination and proofreading process, which may lead to differences between this version and the Version of Record. Please cite this article as doi: 10.1111/eci.12688

This article is protected by copyright. All rights reserved. 
E-mail address: S.D.Garbis@ soton.ac.uk

\title{
Nasser M. Al-Daghri, PhD
}

Biochemistry Department, College of Science, King Saud University, Riyadh, KSA

Email address: ndaghri@ksu.edu.sa

The authors have no conflict of interest to disclose.

Running title: Sex-specific vitamin D effects on blood coagulation

Keywords: Vitamin D, serum proteomics, sexual dimorphism, blood coagulation

\begin{abstract}
Background: Overweight adults are at increased risk for cardiovascular disease and vitamin D deficiency, whereas an important feature to vitamin D physiology is its sex dependence. The aim of this study was to examine whether vitamin D status improvement exerts a sexually dimorphic effect on serum proteins associated with cardiovascular risk among overweight adults.
\end{abstract}

Methods: Unprocessed serum from age- and BMI-matched men $(\mathrm{n}=26)$ and pre-menopausal women $(n=24)$ with vitamin $\mathrm{D}$ deficiency and after they achieved sufficiency through a 12-month nutritional intervention was analyzed using our previously published depletion-free, quantitative proteomics method. Key findings were verified with ELISA. Differentially expressed proteins were subjected to in silico bioinformatics assessment using Principal Component Analysis, hierarchical clustering and Metacore $^{\mathrm{TM}}$ pathway analysis. All mass spectrometry proteomic data are available via

This article is protected by copyright. All rights reserved. 
ProteomeXchange (identifier: PXD003663).

Results: A total of 282 proteins were differentially expressed after the intervention between men and women ( $p$-value $\leq 0.05$ ), in which the blood coagulation pathway was significantly enriched. In agreement with the proteomics findings, ELISA measurements showed vitamin-K dependent protein C, von Willebrand factor, fibrinogen gamma chain and multimerin-1 proteins, of relevance to blood coagulation, to be differentially affected ( $p$-value $\leq 0.05$ ) between sexes after vitamin $\mathrm{D}$ status correction.

Conclusions: This study identified novel protein-level molecular indicators on the sexually dimorphic effect of vitamin D status correction associated with blood coagulation among overweight adults. These sex-mediated vitamin D effects should be factored in the design and interpretation of vitamin D observational and interventional studies testing cardiometabolic outcomes.

\section{Introduction}

Vitamin D deficiency is essentially pandemic, with an estimated one billion people affected worldwide [1]. Apart from its well-established role in calcium and phosphorus homeostasis, vitamin D deficiency has been implicated with adverse extra-skeletal health outcomes, including cardiovascular disease (CVD) [2]. Based on the results of a recent umbrella review, there is suggestive evidence for an association between increased serum vitamin D levels and lower risk of type II diabetes mellitus, hypertension and cardiovascular disease [3]. NHANES III, a cross-sectional study, found an adjusted hazard ratio for CVD mortality of 2.36 (95\% confidence intervals 1.17 to 4.75) after seven years of follow-up, for subjects with $25(\mathrm{OH}) \mathrm{D}$ levels below $25 \mathrm{nmol} / \mathrm{L}$ compared to those with levels over $100 \mathrm{nmol} / \mathrm{L}$ [4]. One more observational study that followed-up 10,000 adults 50 to 74 years old for approximately seven years, showed that subjects with vitamin D deficiency had a $27 \%$ increased risk of total CVD as well as a $62 \%$ increased risk for fatal CVD [5].

This article is protected by copyright. All rights reserved. 
Adults with overweight or obesity are at increased risk for both vitamin D deficiency [6] and CVD [7]. A recent systematic review by the authors highlighted a paucity of vitamin D interventional studies with cardiometabolic risk factors as outcomes among otherwise healthy overweight and obese adults [8]. Within this context, whether vitamin D status improvement, as part of an interventional protocol, exerts sexual dimorphism in pathways associated with cardiovascular disease at the serum protein level has not been examined to date. Recent studies, including the authors', have demonstrated that vitamin D disposition manifests marked sexual dimorphism, also evident through its effects on sex hormone metabolism [9-12].

Recent notable reviews report on the increasing utility of proteomics to various aspects of nutrition research $[13,14]$. In particular, non-targeted, global proteomics could be used to identify novel targets of response to a nutritional intervention at the tissue or serum/plasma level, thus forming the basis to a "hypothesis-generating" strategy [15]. Also, proteomics could be used for the "hypothesis-driven" analysis of a priori selected proteins. A targeted proteomics pipeline has been used in a recent vitamin D observational study examining how vitamin D status differentially affects the expression of 54 high-abundant plasma proteins between hormonal contraceptive users and nonusers [16]. To date, no studies have reported the non-targeted quantitative analysis of serum proteins that become altered consequent to a vitamin $\mathrm{D}$ intervention protocol. This is, in part, consequent to the technically challenging task of effectively analysing the serum proteome to elucidate clinically relevant protein markers [17].

The principle aim of this study was to compare the effects of vitamin D status correction on serum proteins associated with cardiovascular risk, between age- and BMI-matched overweight males and pre-menopausal females using the author's in-depth proteome analysis of non-depleted whole serum $[10,18,19]$.

This article is protected by copyright. All rights reserved. 


\section{Materials and Methods}

\section{Recruitment of participants and intervention}

Reporting of this study conforms to the STROBE statement and the broader EQUATOR guidelines [20]. The authors [21] previously reported the study design and ethics approval by the King Saud University (KSU) Ethics Committee. To adjust for possible seasonal effects on baseline 25(OH)D serum levels, participants were recruited within the months of December and January through advertising in four Primary Health Care Centres (PHCC) of the Riyadh Central Region. A total of 50 (24 female; 26 male) adults (20 to 35 years old) with overweight (BMI from 25 to 30 $\mathrm{kg} / \mathrm{m}^{2}$ ) but otherwise healthy except for vitamin D deficiency $[25(\mathrm{OH}) \mathrm{D}$ levels $<50 \mathrm{nmol} / \mathrm{L}]$ were included (Table 1). This threshold of serum 25(OH)D levels was selected in accordance with the definition of vitamin D deficiency by the Institute of Medicine (IOM) [22]. Patients with obesity, morbid obesity, type 1 or type 2 diabetes, smokers, pregnant or breastfeeding women, postmenopausal women, and subjects taking vitamin or botanical (i.e. St. John's Wort, Ginkgo biloba, Echinacea, etc.) supplements, NSAIDS, aspirin or any other non-prescription medicinal product were excluded from the study. All participants signed an informed consent form. Subjects were asked to return after an overnight fasting for anthropometry and blood withdrawal. This procedure was repeated at 12 months. During the 12-month intervention, subjects were advised to expose themselves to sunlight before 12 am or after 3 pm for 5 to 30 min daily and also encouraged through weekly SMS to increase their daily consumption of vitamin D-rich foods (vitamin D-fortified fresh milk, yoghurt and cheese). Serum levels of $25(\mathrm{OH}) \mathrm{D}$ were used as a reliable surrogate marker of vitamin $\mathrm{D}$ repletion [25(OH)D levels $>50 \mathrm{nmol} / \mathrm{L}]$ [23]. Compliance to the advice for increased sun exposure was assessed through diaries the participants kept for the whole duration of the intervention and questionnaires at baseline and after the end of the intervention. Total energy, macronutrient (carbohydrate, fibre, protein, fat) and micronutrient [saturated fatty acids (SFA), monounsaturated fatty acids (MUFA), polyunsaturated fatty acids (PUFA), vitamin D, calcium] intake were estimated at baseline and after the end of the study using food frequency questionnaires (Supplementary section 1). Physical activity levels of the participants were assessed at baseline and after the end of 
the study in compliance with the Global Physical Activity Questionnaire developed by the WHO [24]

(Supplementary section 2). All participants completed the 12-month intervention.

\section{Anthropometry and blood collection}

Participants were asked to visit their local PHCC physician and/or nurse on duty after overnight fasting (>10 hours) for anthropometry and blood withdrawal. Anthropometry included height (rounded off to the nearest $0.5 \mathrm{~cm}$ ), weight (rounded off to the nearest $0.1 \mathrm{~kg}$ ) and mean systolic and diastolic pressure (average of three readings). Body mass index was calculated as weight (kilograms) divided by squared height (meters ${ }^{2}$ ). Fasting blood samples were collected and immediately transferred to a nonheparinized tube for centrifugation. Collected serum was then transferred to pre-labeled tubes, stored in liquid nitrogen and delivered at the University of Southampton, UK. The samples were subjected to analysis upon arrival without further storage.

\section{Biochemical analyses}

Fasting glucose and lipid profile were measured using a chemical analyser (Konelab, Espoo, Finland). Serum 25(OH)D levels were measured by a specific enzyme-linked immunosorbent assay (IDS, Tyne and Wear, UK). The inter- and intra-assay variability of this assay was $5.2 \%$ and $4.5 \%$, respectively.

\section{Clinical data analysis}

Clinical data were analysed using the Social Sciences version 16.0 (SPSS, Chicago, IL). All parameters are presented as mean \pm standard deviation. A paired Student T-test was used to compare within group differences between baseline and 12 months after the intervention. Significance was set at $p$-value $\leq 0.05$.

This article is protected by copyright. All rights reserved. 


\section{Serum procurement and proteomic analysis}

The procurement and handling of sera was in accordance to the recommendations of the Standard Operating Procedure Integration Working Group (SOPIWG) [25]. The serum specimens were thawed and vortexed for 2 minutes. At baseline and after the 12-month intervention, individual $50 \mu \mathrm{L}$ aliquots from all female participants were randomly selected and combined in two master pools as biological replicates ( $\mathrm{n}=12$ per pool at baseline and at 12-months). The same procedure was applied to sera from male participants ( $\mathrm{n}=13$ per pool at baseline and at 12-months). From each of the eight groups (Females Baseline 1, Females Baseline 2, Females End-of-Study 1, End-of-Study 2, Males Baseline 1, Males Baseline 2, Males End-of-Study 1, Males End-of-Study 2) unprocessed serum was subjected to depletion-free, quantitative serum proteomic analysis using our previously published methodology $[10,18,19]$. Briefly, a $100 \mu \mathrm{L}$ aliquot from each master pool was mixed with $400 \mu \mathrm{L}$ mobile phase solution (6 M guanidine hydrochloride in 9:1 V/V water: methanol) and subjected to high-performance Size Exclusion Chromatography. The separated protein segments were dialysis purified and lyophilized to dryness at $4{ }^{\circ} \mathrm{C}$. An amount of $100 \mu \mathrm{g}$ of protein from each of the corresponding master pools was subjected to trypsin proteolysis and their proteolytic peptides were iTRAQ labeled, pooled, and offline fractionated with high $\mathrm{pH} \mathrm{C}_{8}$ reverse phase chromatography. Each fraction was then analysed with ultra-high performance low $\mathrm{pH} \mathrm{C}_{18}$ nano-liquid chromatography high-resolution tandem mass spectrometry with the FT-Orbitrap platform as reported before [26-30].

Unprocessed raw files were submitted to Proteome Discoverer 1.4 for target decoy searching against the UniProtKB Homo Sapiens database (release date 10-Jan-2015) with SequestHT as reported before. Reporter ion ratios from unique peptides only were considered for the quantitation of the respective protein. Quantification ratios were median-normalized and $\log _{2}$ transformed. A protein was considered differentially expressed between the male and female groups after intervention relative to baseline when its 2 -group T-Test $\mathrm{p}$-value was $\leq 0.05$. Only proteins identified with at least two unique peptides were further considered for bioinformatics analysis in compliance with the Paris Publication Guidelines for the analysis and documentation of peptide and protein identifications

This article is protected by copyright. All rights reserved. 
(http://www.mcponline.org/site/misc/ParisReport_Final.xhtml) and the recently published guidelines for high-confidence protein identification [31]. The mass spectrometry proteomics data have been deposited to the ProteomeXchange Consortium via the PRIDE [32] partner repository with the dataset identifier PXD003663.

\section{Principal component analysis and protein hierarchical clustering analysis}

Principal component analysis using the reporter ion ratios of all analyzed proteins after the 12-month intervention compared to baseline was performed using BioConductor-R (version 2.15.1) and g-plots in $\mathrm{R}$ (version 3.1.2). Hierarchical clustering analysis visualized in heatmap format using the differentially expressed proteins between the male and female groups after the 12-month intervention compared to baseline was performed using the Cluster 3.0 (http://bonsai.hgc.jp/ mdehoon/software/cluster/software.htm) and the Java Treeview software (http://jtreeview.sourceforge.net). The clustering parameters were iteratively determined to be: correlation (Euclidean distance) metrics and complete linkage method using the normalized log2ratios for each protein.

\section{Pathway Map analysis}

The in silico functional interpretation of the modulated serum proteome between the male and female groups was conducted with the pathway map analysis feature of MetaCore (GeneGo, St. Joseph, MI, US). A hypergeometric test was used for the identification of canonical pathway maps that were enriched in the differentially expressed serum proteins between sexes (Benjamini-Hochberg FDR-corrected, $\mathrm{p}$-value $\leq 0.05)$.

This article is protected by copyright. All rights reserved. 


\section{ELISA measurements}

ELISA measurements for the proteins vitamin-K dependent protein $\mathrm{C}$ (MyBioSource, catalogue number MBS5703600, dilution 1:200), von Willebrand factor (Abcam, Cambridge, UK, catalogue number ab108918), fibrinogen gamma chain (Abcam, Cambridge, UK, catalogue number ab108842, dilution 1:1000) and multimerin-1 (USCN, catalogue number SEC622Hu, dilution 1:5) were performed on individual serum samples of females and males at baseline and after the 12-month intervention following the manufacturer's instructions. These subjects were randomly selected from the cohort using the randomization function of Excel, Microsoft Office 2011. Due to insufficient sample volume from certain subjects, the number of serum samples analysed for each ELISA measurement were as follows: vitamin-K dependent protein $\mathrm{C}(\mathrm{n}=23$ females and $\mathrm{n}=23$ males); von Willebrand factor; Fibrinogen gamma chain ( $n=20$ females and $n=20$ males) and multimerin- $1(n=22$ females and $n=22$ males). Delta values of change (end-of-study minus baseline) were compared between female and male participants using a heteroscedastic two-group T-Test. Significance was set at $\mathrm{p}$-value $\leq 0.05$.

\section{Results}

The participants' clinical characteristics, sun exposure, physical activity and nutritional assessment data at baseline and after the 12-month intervention are detailed in Table 1. Serum $25(\mathrm{OH}) \mathrm{D}$ levels was the only assessed clinical indicator that changed significantly as a result of the intervention. With the exception of vitamin D intake and sun exposure, there was no significant change in physical activity levels, total energy, macronutrient and micronutrient intake between baseline and end-of-study for both female and male groups (Table 1).

Only proteins identified at $\geq 95 \%$ confidence (FDR corrected p-value $\leq 0.05$ at the peptide level) were accounted for. A total of 1,841 unique proteins were fully quantified across all eight conditions of the multiplex experiment (Supplementary Table 1). Principal component analysis of 
the reporter ion ratios of analysed proteins showed that females clustered separately from males (Figure 1A), suggesting that vitamin D status improvement exerts sexually dimorphic effects at the serum protein level.

A total of 282 proteins identified with at least two unique peptides were differentially expressed after the intervention between females and males ( $\mathrm{p}$-value $\leq 0.05)($ Supplementary Table 2). These are visualized in heatmap format in Figure 1B. The blood coagulation pathway was significantly enriched in the differentially expressed proteins between the two sexes after the vitamin D intervention $($ FDR corrected p-value $=9.9 \mathrm{E}-22)($ Figure 2). Representative proteins of the blood coagulation pathway were measured with ELISA to individual serum specimens within the same clinical cohort (delta value $=$ end-of-study minus baseline): vitamin-K dependent protein $\mathrm{C}[$ Mean delta value \pm SD: $-3.2 \pm 11.0 \mathrm{ng} / \mathrm{mL}$ in females and $2.2 \pm 6.5 \mathrm{ng} / \mathrm{mL}$ in males; $\mathrm{p}$-value $=0.05$ between sexes], von Willebrand factor [Mean delta value \pm SD: $120.8 \pm 288.2$ U/L in females and $-62.5 \pm 294.1$ $\mathrm{U} / \mathrm{L}$ in males; $\mathrm{p}$-value $=0.04$ between sexes], fibrinogen gamma chain [Mean delta value $\pm \mathrm{SD}$ : $2.6 \pm 6.9 \mu \mathrm{g} / \mathrm{mL}$ in females and $-0.6 \pm 1.4 \mu \mathrm{g} / \mathrm{mL}$ in males; $\mathrm{p}$-value $=0.05$ between sexes $]$ and multimerin-1 [Mean delta value \pm SD: $-1.2 \pm 5.6 \mathrm{ng} / \mathrm{mL}$ in females and $12.8 \pm 29.6 \mathrm{ng} / \mathrm{mL}$ in males; $\mathrm{p}$ value $=0.04$ between sexes] (Figures 2 and 3) (Supplementary Table 3). Their ELISA measurements were in agreement with the differential expression observed with serum proteomics: vitamin-K dependent protein C [Mean iTRAQ $\log 2$ ratio end-of-study/baseline \pm SD: $0.09 \pm 0.09$ in females and $0.41 \pm 0.16$ in males; $p$-value $=0.02$ between sexes], von Willebrand factor [Mean iTRAQ $\log 2$ ratio end-of-study/baseline \pm SD: $-0.05 \pm 0.06$ in females and $-0.21 \pm 0.07$ in males; $p$-value $=0.01$ between sexes], fibrinogen gamma chain [Mean iTRAQ log2ratio end-of-study/baseline \pm SD: $0.03 \pm 0.13$ in females and $-0.37 \pm 0.06$ in males; $p$-value $=0.001$ between sexes $]$ and multimerin- 1 [Mean iTRAQ $\log 2$ ratio end-of-study/baseline \pm SD: $-0.16 \pm 0.24$ in females and $0.29 \pm 0.08$ in males; p-value $=0.03$ between sexes $]$.

This article is protected by copyright. All rights reserved. 


\section{Discussion}

The present non-targeted serum proteomics prospective interventional study showed that vitamin D status improvement among overweight adults exerts sex-specific effects on proteins participating in the blood coagulation pathway. To date, only few studies have examined the sex specificity of the pleiotropic actions of vitamin D. A recent cross-sectional study reported sexually dimorphic trends between vitamin D status and its role in conditioning the severity of coronary artery disease [33]. Interestingly, this study observed that lower 25(OH)D levels played a more pronounced role in conditioning the severity of coronary artery disease in females compared to males. Another cross-sectional study examined the association between vitamin D deficiency and the associated risk of developing obesity-related complications, including type II diabetes mellitus (T2DM) and insulin resistance [9]. After adjusting for confounding factors, including BMI, the study showed an inverse association of 25(OH)D with T2DM only in females, suggesting a sex-specific extra-skeletal effect of vitamin D. We have previously reported that vitamin D supplementation in patients with T2DM improved serum concentrations of magnesium and selenium in a sex-specific manner [34].

Two different parameters could in isolation or synergistically explain this sexually dimorphic vitamin D action and its effect to blood coagulation. Firstly, our group has shown previously that among overweight/obese adults, males exhibited higher circulating levels of proteins involved in the blood coagulation pathway relative to females [10]. Secondly, this same study provided protein level evidence of the increased conversion of 25-hydroxyvitamin D to the active metabolite 1,25 hydroxyvitamin D in men compared to women. These traits may be linked to the effects of sex hormone metabolism on vitamin D disposition [35, 36] and the blood coagulation system [37-39]. In accordance to the current mandates of the U. S. National Institutes of Health (NIH), sex specific differences in the metabolism and disposition of vitamin D should be taken into consideration in cell and animal studies [40].

This article is protected by copyright. All rights reserved. 
A potential limitation to the experimental study design was the sample pooling for each clinical condition examined. To overcome this limitation, key proteins were validated with ELISA in individual serum samples from the same clinical cohort. Another limitation to this study is the physiological interpretation of the sexual dimorphic trend observed. Such an investigation was beyond the scope of this study. Finally, the number of subjects that participated in the present proofof-principle study is rather small and a non-treated control group was not included, thus further confirmation of our findings in randomized control trials including larger number of normal weight as well as overweight/obese subjects is warranted.

\section{Conclusions and Future Outlook}

The quantitative serum proteomics approach used in this study revealed a sexually dimorphic effect of vitamin D status correction on proteins participating in blood coagulation among overweight adults. These sex-mediated vitamin D effects should be factored in the design and interpretation of vitamin D observational and interventional studies testing cardiometabolic outcomes.

\section{Acknowledgments}

We are indebted to Mr. Roger Allsopp and Mr. Derek Coates for their enthusiasm, fund raising, and vision in establishing the clinical proteomics laboratory at the University of Southampton, Divisions for Cancer Sciences and Clinical Experimental Medicine. Funding: The International Highly Cited Research Group (IHCRG 14-203) of the Deanship of Scientific Research, the Vice-Dean of Scientific Research Chairs and the Visiting Professor Program of King Saud University, Riyadh, Saudi Arabia, Wessex Cancer Trust and Medical Research,U.K.

This article is protected by copyright. All rights reserved. 


\section{References}

1. Holick MF and Chen TC. Vitamin D deficiency: a worldwide problem with health consequences. Am J Clin Nutr 2008; 87: 1080S-6S.

2. Pludowski P, Holick MF, Pilz S, Wagner CL, Hollis BW, Grant WB, et al. Vitamin D effects on musculoskeletal health, immunity, autoimmunity, cardiovascular disease, cancer, fertility, pregnancy, dementia and mortality-a review of recent evidence. Autoimmun Rev 2013; 12 : 976-89.

3. Theodoratou E, Tzoulaki I, Zgaga L, Ioannidis JP. Vitamin D and multiple health outcomes: umbrella review of systematic reviews and meta-analyses of observational studies and randomised trials. BMJ 2014; 348: g2035.

4. Ginde AA, Scragg R, Schwartz RS, Camargo CA. Prospective study of serum 25hydroxyvitamin D level, cardiovascular disease mortality, and all-cause mortality in older U.S. adults. J Am Geriatr Soc 2009; 57: 1595-603.

5. Perna L, Schöttker B, Holleczek B, Brenner H. Serum 25-hydroxyvitamin D and incidence of fatal and nonfatal cardiovascular events: a prospective study with repeated measurements. J Clin Endocrinol Metab 2013; 98: 4908-15.

6. Saneei P, Salehi-Abargouei A, Esmaillzadeh A. Serum 25-hydroxy vitamin D levels in relation to body mass index: a systematic review and meta-analysis. Obes Rev 2013; 14: 393404.

7. Fan J, Song Y, Chen Y, Hui R, Zhang W. Combined effect of obesity and cardio-metabolic abnormality on the risk of cardiovascular disease: A meta-analysis of prospective cohort studies. Int J Cardiol 2013; 168: 4761-8.

This article is protected by copyright. All rights reserved. 
8. Manousopoulou A, Al-Daghri NM, Garbis SD and Chrousos GP. Vitamin D and cardiovascular risk among adults with obesity: a systematic review and meta-analysis. Eur J Clin Invest 2015; 45: 1113-26.

9. Stadlmayr A, Aigner E, Huber-Schonauer U, Niederseer D, Zwerina J, Husar-Memmer E, et al. Relations of vitamin D status, gender and type 2 diabetes in middle-aged Caucasians. Acta Diabetol 2015; 52: 39-46.

10. Al-Daghri NM, Al-Attas OS, Johnston HE, Singhania A, Alokail MS, Alkharfy KM, et al. Whole serum 3D LC-nESI-FTMS quantitative proteomics reveals sexual dimorphism in the milieu interieur of overweight and obese adults. J Proteome Res 2014; 13: 5094-105.

11. Lerchbaum E and Obermayer-Pietsch B. Vitamin D and fertility: a systematic review. Eur J Endocrinol 2012; 166: 765-78.

12. Wehr E, Pilz S, Boehm BO, Marz W and Obermayer-Pietsch B. Association of vitamin D status with serum androgen levels in men. Clin Endocrinol (Oxf) 2010; 73: 243-8.

13. Kussmann M, Panchaud A and Affolter M. Proteomics in nutrition: status quo and outlook for biomarkers and bioactives. J Proteome Res 2010; 9: 4876-87.

14. Moresco JJ, Dong MQ and Yates JR 3rd. Quantitative mass spectrometry as a tool for nutritional proteomics. Am J Clin Nutr 2008; 88: 597-604.

15. Al-Daghri NM, Garbis SD. The need for serological markers of response to vitamin D status optimization: a case for quantitative serum proteomics. Bioanalysis. 2014; 6: 721-3

16. Garcia-Bailo B, Jamnik J, Da Costa LA, Borchers CH, Badawi A and El-Sohemy A. Plasma 25-hydroxyvitamin D, hormonal contraceptive use, and the plasma proteome in Caucasian, East Asian, and South Asian young adults. J Proteome Res 2013; 12: 1797-807.

17. Hanash SM, Pitteri SJ, Faca VM. Mining the plasma proteome for cancer biomarkers. Nature 2008; 452: 571-9.

This article is protected by copyright. All rights reserved. 
18. Garbis SD, Roumeliotis TI, Tyritzis SI, Zorpas KM, Pavlakis K and Constantinides CA. A novel multidimensional protein identification technology approach combining protein size exclusion prefractionation, peptide zwitterion-ion hydrophilic interaction chromatography, and nano-ultraperformance RP chromatography/nESI-MS2 for the in-depth analysis of the serum proteome and phosphoproteome: application to clinical sera derived from humans with benign prostate hyperplasia. Anal Chem 2011; 83: 708-18.

19. Larkin SE, Johnston HE, Jackson TR, Jamieson DG, Roumeliotis TI, Mockridge CI et al. Detection of candidate biomarkers of prostate cancer progression in serum: a depletion-free 3D LC/MS quantitative proteomics pilot study. Br J Cancer 2016; doi: 10.1038/bjc.2016.291. [Epub ahead of print]

20. Simera I, Moher D, Hoey J, Schulz KF, Altman DG. A catalogue of reporting guidelines for health research. Eur J Clin Invest 2010; 40: 35-53.

21. Al-Daghri NM, Alkharfy KM, Al-Saleh Y, Al-Attas OS, Alokail MS, Al-Othman A, et al. Modest reversal of metabolic syndrome manifestations with vitamin D status correction: a 12month prospective study. Metabolism 2012; 61: 661-6.

22. Ross AC, Manson JE, Abrams SA, Aloia JF, Brannon PM, Clinton SK, et al. The 2011 report on dietary reference intakes for calcium and vitamin D from the Institute of Medicine: what clinicians need to know. J Clin Endocrinol Metab 2011; 96: 53-8.

23. Heaney RP. Serum 25-hydroxyvitamin D is a reliable indicator of vitamin D status. Am J Clin Nutr 2011; 94: 619-20; author reply 20.

24. Cleland CL, Hunter RF, Kee F, Cupples ME, Sallis JF and Tully MA. Validity of the global physical activity questionnaire (GPAQ) in assessing levels and change in moderate-vigorous physical activity and sedentary behaviour. BMC Public Health 2014; 14: 1255.

25. Tuck MK, Chan DW, Chia D, Godwin AK, Grizzle WE, Krueger KE, et al. Standard operating procedures for serum and plasma collection: early detection research network 
consensus statement standard operating procedure integration working group. J Proteome Res 2009; 8: 113-7.

26. Manousopoulou A, Saito S, Yamamoto Y, Al-Daghri NM, Ihara M, Carare RO, et al. Hemisphere asymmetry of response to pharmacologic treatment in an Alzheimer's disease mouse model. J Alz Dis 2016; 51: 333-8.

27. Manousopoulou A, Koutmani Y, Karaliota S, Woelk CH, Manolakos ES, Karalis K, et al. Hypothalamus proteomics from mouse models with obesity and anorexia reveals therapeutic targets of appetite regulation. Nutr Diabetes 2016; 6: e204.

28. Manousopoulou A, Woo J, Woelk CH, Johnston HE, Singhania A, Hawkes C, et al. Are you also what your mother eats? Distinct proteomic portrait as a result of maternal high-fat diet in the cerebral cortex of the adult mouse. Int J Obes (Lond) 2015; 39: 1325-8.

29. Giannogonas P, Apostolou A, Manousopoulou A, Theocharis S, Macari SA, Psarras S, et al. Identification of a novel interaction between corticotropin releasing hormone (Crh) and macroautophagy. Sci Rep 2016; 6: 23342.

30. Hanley CJ, Noble F, Ward M, Bullock M, Drifka C, Mellone M, et al. A subset of myofibroblastic cancer-associated fibroblasts regulate collagen fiber elongation, which is prognostic in multiple cancers. Oncotarget 2016; 7: 6159-74.

31. Omenn GS, Lane L, Lundberg EK, Beavis RC, Nesvizhskii AI and Deutsch EW. Metrics for the Human Proteome Project 2015: Progress on the Human Proteome and Guidelines for High-Confidence Protein Identification. J Proteome Res 2015; 14: 3452-60.

32. Vizcaino JA, Deutsch EW, Wang R, Csordas A, Reisinger F, Rios D, et al. ProteomeXchange provides globally coordinated proteomics data submission and dissemination. Nat Biotechnol 2014; 32: 223-6

This article is protected by copyright. All rights reserved. 
33. Verdoia M, Schaffer A, Barbieri L, Di Giovine G, Marino P, Suryapranata H, et al. Impact of gender difference on vitamin D status and its relationship with the extent of coronary artery disease. Nutr Metab Cardiovasc Dis 2015; 25: 464-70.

34. Al-Daghri NM, Alkharfy KM, Khan N, Alfawaz HA, Al-Ajlan AS, Yakout SM, et al. Vitamin D supplementation and serum levels of magnesium and selenium in type 2 diabetes mellitus patients: gender dimorphic changes. Int J Vitam Nutr Res 2014; 84: 27-34.

35. Lee DM, Tajar A, Pye SR, Boonen S, Vanderschueren D, Bouillon R, et al. Association of hypogonadism with vitamin D status: the European Male Ageing Study. Eur J Endocrinol 2012; 166: 77-85.

36. Bertone-Johnson ER, Chocano-Bedoya PO, Zagarins SE, Micka AE and Ronnenberg AG. Dietary vitamin D intake, 25-hydroxyvitamin D3 levels and premenstrual syndrome in a college-aged population. J Steroid Biochem Mol Biol 2010; 121: 434-7.

37. Miller VM, Jayachandran M and Owen WG. Ageing, oestrogen, platelets and thrombotic risk. Clin Exp Pharmacol Physiol 2007; 34: 814-21.

38. Cano A and Van Baal WM. The mechanisms of thrombotic risk induced by hormone replacement therapy. Maturitas 2001; 40: 17-38.

39. De Pergola G, De Mitrio V, Sciaraffia M, Pannacciulli N, Minenna A, Giorgino F, et al. Lower androgenicity is associated with higher plasma levels of prothrombotic factors irrespective of age, obesity, body fat distribution, and related metabolic parameters in men. Metabolism 1997; 46: 1287-93.

40. Clayton JA and Collins FS. Policy: NIH to balance sex in cell and animal studies. Nature 2014; 509: 282-3.

This article is protected by copyright. All rights reserved. 
Table 1. Clinical characteristics of study subjects

\begin{tabular}{|c|c|c|c|c|}
\hline & \multicolumn{2}{|c|}{ Females } & \multicolumn{2}{|c|}{ Males } \\
\hline & Baseline & Follow-Up & Baseline & Follow-Up \\
\hline $\mathbf{N}$ & \multicolumn{2}{|c|}{24} & \multicolumn{2}{|c|}{26} \\
\hline Age (years) & \multicolumn{2}{|c|}{$26.2 \pm 4.4$} & \multicolumn{2}{|c|}{$30.3 \pm 4.6$} \\
\hline BMI $\left(\mathrm{kg} / \mathrm{m}^{2}\right)$ & $27.6 \pm 1.9$ & $27.2 \pm 2.8$ & $28.4 \pm 1.6$ & $27.5 \pm 2.2$ \\
\hline Sun exposure (hr/week) & $1.1 \pm 0.2$ & $4.2 \pm 0.3 *$ & $0.5 \pm 0.3$ & $3.5 \pm 0.4^{* *}$ \\
\hline Physical activity (MET-min/week) & $540 \pm 280$ & $490 \pm 315$ & $702 \pm 308$ & $650 \pm 240$ \\
\hline Energy intake (kcal/d) & $1841 \pm 880$ & $1894 \pm 520$ & $2059 \pm 210$ & $2082 \pm 195$ \\
\hline Carbohydrate intake (g/d) & $294 \pm 138$ & $310 \pm 140$ & $333 \pm 130$ & $339 \pm 125$ \\
\hline Fibre intake (g/d) & $17 \pm 10$ & $18 \pm 9$ & $16.5 \pm 8.5$ & $17 \pm 10$ \\
\hline Protein intake (g/d) & $73 \pm 31$ & $69 \pm 28$ & $75 \pm 35$ & $77 \pm 32$ \\
\hline Fat intake $(g / d)$ & $49 \pm 23$ & $50 \pm 27$ & $55 \pm 40$ & $54 \pm 38$ \\
\hline Dietary SFA intake (g/d) & $15.7 \pm 9.0$ & $16.2 \pm 8.8$ & $18.7 \pm 11.4$ & $18.0 \pm 12.6$ \\
\hline Dietary MUFA intake (g/d) & $17.3 \pm 9.4$ & $16.9 \pm 8.5$ & $19.1 \pm 12.7$ & $19.5 \pm 11.6$ \\
\hline Dietary PUFA intake (g/d) & $11.5 \pm 7.0$ & $12.0 \pm 6.5$ & $13.4 \pm 10.1$ & $13.0 \pm 10.5$ \\
\hline Dietary calcium intake (mg/d) & $910 \pm 350$ & $872 \pm 295$ & $785 \pm 180$ & $805 \pm 223$ \\
\hline Dietary vitamin D intake ( $\mu \mathrm{g} / \mathrm{d})$ & $0.6 \pm 0.2$ & $21.1 \pm 4.7^{* *}$ & $1.2 \pm 0.5$ & $19.3 \pm 6.4 * *$ \\
\hline Systolic blood pressure (mmHg) & $115.0 \pm 13.8$ & $118.0 \pm 9.5$ & $122.0 \pm 14.8$ & $110.0 \pm 10.0$ \\
\hline Diastolic blood pressure (mmHg) & $80.0 \pm 10.9$ & $80.0 \pm 4.3$ & $77.0 \pm 6.7$ & $73.0 \pm 5.7$ \\
\hline Glucose $(\mathbf{m m o l} / \mathbf{L})$ & $5.4 \pm 1.23$ & $5.6 \pm 1.07$ & $5.8 \pm 0.75$ & $5.9 \pm 0.74$ \\
\hline Triglycerides $(\mathrm{mmol} / \mathrm{L})$ & $1.69 \pm 0.70$ & $2.2 \pm 1.1$ & $1.8 \pm 0.66$ & $1.4 \pm 0.46$ \\
\hline
\end{tabular}

This article is protected by copyright. All rights reserved. 


\begin{tabular}{lcccc}
\hline Total-Cholesterol (mmol/L) & $5.4 \pm 1.23$ & $5.6 \pm 1.07$ & $5.3 \pm 0.55$ & $4.8 \pm 0.43$ \\
HDL-Cholesterol (mmol/L) & $0.96 \pm 0.25$ & $0.92 \pm 0.24$ & $0.75 \pm 0.24$ & $0.94 \pm 0.21$ \\
LDL-Cholesterol (mmol/l) & $0.43 \pm 0.24$ & $0.34 \pm 0.28$ & $0.48 \pm 0.11$ & $0.48 \pm 0.08$ \\
$\mathbf{2 5}(\mathbf{O H}) \mathbf{( n m o l} / \mathbf{L})$ & $17.4 \pm 6.7$ & $65.4 \pm 14.4 * *$ & $19.2 \pm 5.2$ & $61.6 \pm 9.8^{* * *}$ \\
\hline
\end{tabular}

Note: Data presented as mean \pm standard deviation; $*$ denotes significance at 0.05 level; ** denotes significance at 0.01 level; p-value significant at $<0.05$. A paired T-test was performed to compare differences between baseline and after 1 year intervention. Abbreviations: MET (metabolic equivalent of task); SFA (saturated fatty acids); MUFA (mono-unsaturated fatty acids); PUFA (polyunsaturated fatty acids); HDL (high-density lipoprotein); LDL (low-density lipoprotein).

\section{Figure Legends}

Figure 1. A. Principal component analysis of the reporter ion ratios of all profiled proteins showed that females clustered separately from males following the 12-month vitamin D intervention. B. Hierarchical clustering analysis visualized in heatmap format of differentially expressed serum proteins between females and males following the 12-month vitamin $\mathrm{D}$ intervention ( $\mathrm{p}$-value $\leq 0.05$ )

Figure 2. The blood coagulation pathway was found to be significantly enriched in the differentially expressed proteins between males and females following the 12-month vitamin D intervention. Analysed proteins are denoted with a thermometer. Red=up-regulation; Blue=down-regulation; $\mathrm{F}=$ Females end-of-study vs. baseline; $\mathrm{M}=$ Males end-of-study vs. baseline. Circled proteins were verified with ELISA in individual samples.

This article is protected by copyright. All rights reserved. 
Figure 3. Proteomic results (iTRAQ $\log 2$ ratios of unique peptides: end-of-study vs. baseline) for the biological replicates of pooled samples ( $n=24$ females; $n=26$ males) and respective validation with ELISA (delta value: end-of-study minus baseline) in individual serum samples of females and males $(\mathrm{n}=20$ to 23 ) for: A. Vitamin-K dependent protein $\mathrm{C}$ [Proteomics: mean iTRAQ log2ratio \pm SD: $0.09 \pm 0.09$ in females and $0.41 \pm 0.16$ in males; $p$-value $=0.02$ between sexes; ELISA: mean delta value \pm SD: $-3.2 \pm 11.0 \mathrm{ng} / \mathrm{mL}$ in females and $2.2 \pm 6.5 \mathrm{ng} / \mathrm{mL}$ in males; $\mathrm{p}$-value $=0.05$ between sexes], von Willebrand factor [Proteomics: mean iTRAQ $\log 2$ ratio \pm SD: $-0.05 \pm 0.06$ in females and $-0.21 \pm 0.07$ in males; -value $=0.01$ between sexes; ELISA: mean delta value \pm SD: $120.8 \pm 288.2 \mathrm{U} / \mathrm{L}$ in females and $-62.5 \pm 294.1 \mathrm{U} / \mathrm{L}$ in males; $\mathrm{p}$-value $=0.04$ between sexes], fibrinogen gamma chain [Proteomics: mean iTRAQ $\log 2$ ratio \pm SD: $0.03 \pm 0.13$ in females and $-0.37 \pm 0.06$ in males; $p$-value $=0.001$ between sexes; ELISA: mean delta value \pm SD: $2.6 \pm 6.9 \mu \mathrm{g} / \mathrm{mL}$ in females and $-0.6 \pm 1.4 \mu \mathrm{g} / \mathrm{mL}$ in males; $\mathrm{p}$-value $=0.05$ between sexes] and multimerin-1 [Proteomics: mean iTRAQ log2ratio \pm SD: $-0.16 \pm 0.24$ in females and $0.29 \pm 0.08$ in males; -value $=0.03$ between sexes; ELISA: mean delta value \pm SD: $1.2 \pm 5.6 \mathrm{ng} / \mathrm{mL}$ in females and $12.8 \pm 29.6 \mathrm{ng} / \mathrm{mL}$ in males; $\mathrm{p}$-value $=0.04$ between sexes $]$.

This article is protected by copyright. All rights reserved. 
A

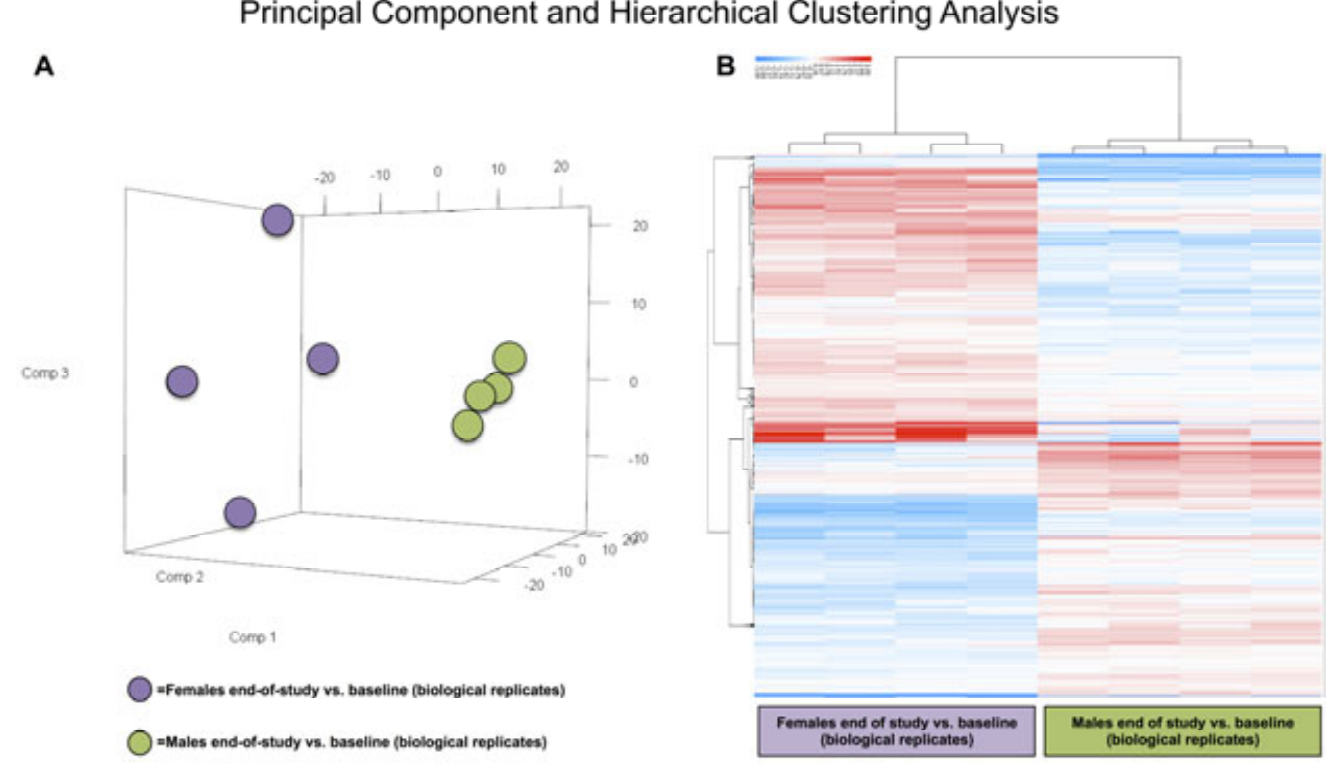

Principal Component and Hierarchical Clustering Analysis
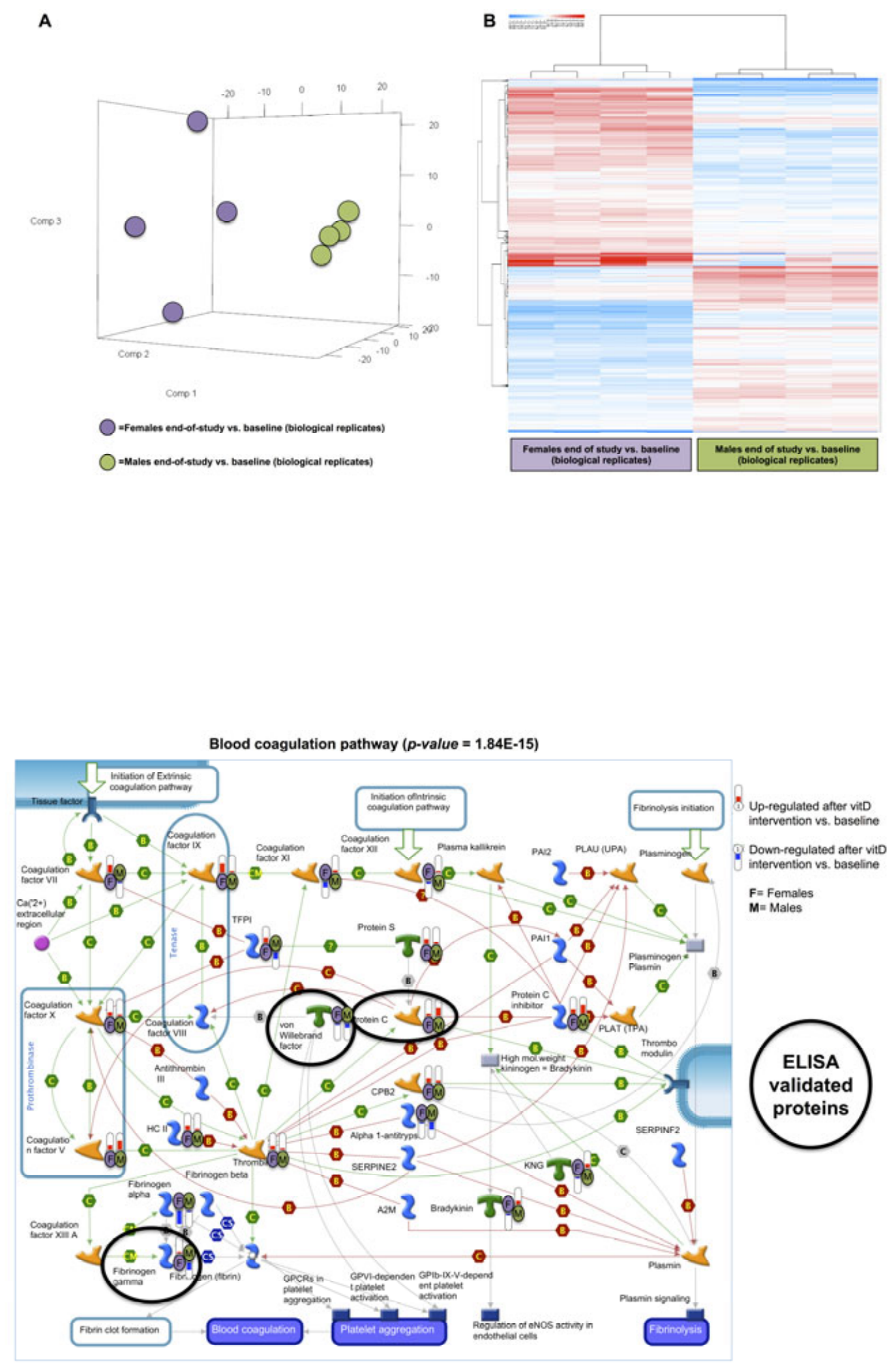

This article is protected by copyright. All rights reserved. 
Validation of key proteins participating in blood coagulation with ELISA
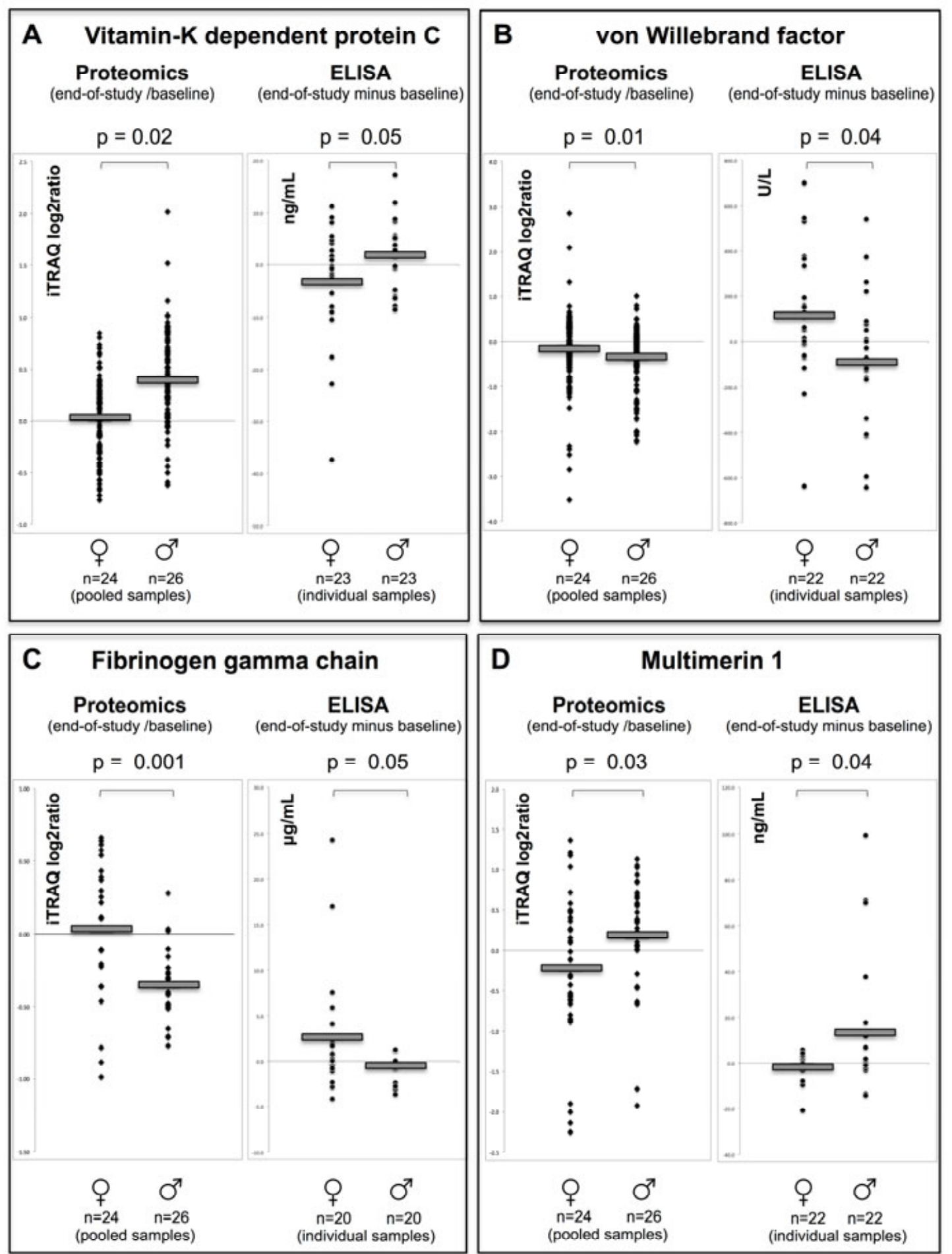

This article is protected by copyright. All rights reserved. 